\title{
Typos de pretos: escravos na fotografia de Christiano Jr
}

Resumo

O presente artigo tem como objetivo analisar parte da obra do fotógrafo Christiano Júnior, português que viveu no Brasil na segunda metade do século XIX. As imagens que aqui apresentamos e analisamos são extremamente relevantes e se originam de uma demanda bem específica, as fotografias de tipos populares. Christiano fez algumas dezenas de retratos da população escrava que vivia na cidade do Rio de Janeiro, na década de 1860. Tais fotografias são hoje uma oportunidade única para conhecer essa população e conhecer suas características.

Palavras-chave:

Fotografia, escravos, Brasil Imperial 


\title{
Types of black: slaves in photography Christiano Jr
}

\section{MARCELO EDUARDO LEITE}

\begin{abstract}
This paper aims to analyze part of Christiano Júnior's works, who lived in Brazil during the second half of the nineteenth century. The images here presented and analyzed are extremely relevant, they were originated from a specific demand, that means photographs of a popular type. Christiano produced some of the several portraits of the slave population, which lived in Rio de Janeiro city during the 186o's. Today such photographs are the only opportunity to know this population and its traits.
\end{abstract}

Keywords: Photography, slaves, Brazil Imperial 


\section{Apresentação}

O presente artigo tem como objetivo apresentar a produção do fotógrafo Christiano Júnior, realizada na cidade do Rio de Janeiro na década de 186o. Tais imagens são exemplos contundentes de uma forma muito comum de fotografia no século XIX, as cartes de visite de tipos exóticos ou populares. Sendo, também, referência para que possamos compreender o universo dos escravos de ganho que habitavam as ruas da cidade.

Nossa abordagem compreende o fotógrafo como um mediador que interpreta o campo da cultura, fazendo uma leitura específica do mesmo. Nos termos de Kossoy, "O processo de criação do fotógrafo engloba a aventura estética, cultural e técnica que irá originar a representação fotográfica." (1999, p. 26). Assim, a fotografia pode ser entendida como um documento e, também, como uma representação da realidade.

A fotografia implica uma transposição de realidades: é a transposição da realidade visual do assunto selecionado, no contexto da vida (primeira realidade), para a realidade da representação (imagem fotográfica: segunda realidade); trata-se pois, também, de uma transposição de dimensões (KOSSOY, 1999, p. 37).

Desta forma, a fotografia como objeto de nossa análise requer uma investigação que observe além das questões técnicas, outros elementos, se aproximando do meio no qual tal representação é feita, entendendo seus sentidos específicos. Por conta disso que nossa missão de compreender as fotografias de Christiano Júnior nos convida a conhecer mais sobre a sociedade na qual ela é produzida, compreendendo melhor seus significados e formas de representar a realidade. 


\section{As fotografias carte de visite}

Difundidas a partir do ano de 1854, as cartes de visite são fotografias realizadas em estúdio, e que foram desenvolvidas pelo francês André Disdéri. Filho de um imigrante que se muda à Paris no intento de fazer fortuna, Disdéri é o primeiro a apreender as exigências do momento e os meios de satisfazer novas demandas, já que ele percebe que a fotografia, por ser muito cara, era apenas acessível à reduzida classe dos ricos. Cioso da importância operacional do estúdio como um fator determinante para o seu sucesso comercial, constata que os elevados preços cobrados, devido ao uso de grandes formatos, além de não permitirem acompanhar a vontade popular, obrigam o fotógrafo a despender mais tempo no processo de revelação. Ao compreender essas variantes, o que revela o seu tino prático e comercial, ele percebe que o ofício não daria resultados, a menos que conseguisse ampliar a sua clientela e aumentar as encomendas de retratos. É quando tem a ideia de desenvolver as cartes de visite (FREUND, 1986, p. 69). Tais retratos, medindo aproximadamente $5 \times 9$ centímetros, tem como principal inovação o fato de serem produzidos em série, a partir de um sistema de lentes múltiplas. O que permite ao cliente sair do ateliê fotográfico com uma série de imagens idênticas, nas quais se explicita a projeção pessoal do retratado. $\mathrm{O}$ retratado pode adquirir 12, 24 ou 36 imagens iguais, podendo, inclusive, voltar ao ateliê para encomendar mais cópias, já que o negativo fica arquivado no estabelecimento. Uma vez com sua série de imagens nas mãos, o cliente divulga esta sua imagem construída. Como o próprio nome diz, trata-se de um 'cartão de visita'. É dada como lembrança e, muitas vezes, trocada entre as pessoas. Com sua grande difusão, aparecem alguns colecionadores que as colam em álbuns, arquivando-as. Surgem, também, aquelas que são vendidas em livrarias, tais como as de 'tipos exóticos', que retratavam tipos populares como índios e escravos, e as de celebridades, com figuras ilustres, como por exemplo, religiosos, políticos e artistas.

Uma das principais inovações das cartes de visite é o retrato de 'corpo inteiro', o que implica cercar o retratado de artifícios teatrais que definem seu status, longe do indivíduo e próximo da máscara social, numa paródia de auto-representação na qual se unem realismo e idealização. Estes retratos são a forma mais completa de junção da série de elementos mobilizados na elaboração da cena fotográfica. Também, ne- 
les se observa que os clientes podem introduzir a sua própria indumentária, trazendo desde objetos cotidianos à roupa do dia-a-dia, ostentando traços da moda desejada, já que os ateliês oferecem vestimentas muitas vezes inacessíveis a eles. A verdade é que estas pessoas procuram, por meio desses objetos, contar a sua própria história: muitos querem ser retratados com as suas ferramentas de trabalho, com seu ícone pessoal. Estes retratos agregam os fragmentos da personalidade do indivíduo, que são incorporados e reincorporados na sala de poses, local onde se estabelece a construção individual.

No tocante à difusão das cartes de visite no Brasil devemos, de imediato, considerar as singularidades de sua expansão no país. Aqui, este suporte chega e atinge novos segmentos da população, mesmo tendo sido difundido de forma bem mais restrita que na Europa. Segmentos, estes, que podem se fazer representar, finalmente. Podemos exemplificar entre a clientela, o negro liberto, o imigrante, o trabalhador urbano, a elite agrária etc. Assim, devemos estar atentos às singularidades deste material.

Neste sentido, observamos que à primeira vista as fotografias oitocentistas parecem homogêneas; entretanto, um olhar mais aprofundado sobre elas, assim como um exame atento da bibliografia existente mostram a coexistência de formas de uso diferenciadas. Esta diversidade é fruto, principalmente, de dois fatores: as transformações técnicas da própria fotografia e as mudanças sociais. Considerando que novos anseios e novos padrões geram novas representações, nossa proposta vislumbra um estudo pontual.

Fazendo este percurso da totalidade para o recorte, a proposta que apresentamos demonstra as especificidades do material nacional que, a nosso ver, mesmo tendo concomitância com as elaborações cênicas de outros locais, por oferecer também uma lógica definida de elaborações cênicas comuns: pose, indumentárias, formatos e meios de difusão, nos proporciona outro ângulo de observação, que vem dos fotógrafos e suas peculiaridades. Ou seja, a lógica, além de não minimizar o papel do fotógrafo como mediador, ainda permite que ele seja fundamental na geração do produto final, a fotografia carte de visite. No mesmo sentido, notamos que, em alguns casos as interferências dos fotógrafos são observáveis, em outras, é a sua não interferência que aparece. Como por exemplo, ao não esconder sinais que denunciam uma roupa emprestada pelo ateliê, ou na adaptação de objetos cênicos, ou abrindo espaço a segmentos que não seriam habitués em 
outros estabelecimentos. Assim, fomos notando que, cada profissional desenvolve seu ofício dentro de alguns parâmetros, e, no contexto de um universo mais abrangente, vemos algumas diferenças entre as produções.

Com relação ao estudo das cartes de visite é bom salientar que devemos, em primeiro lugar, conceder atenção à cena social e ao décor interno: equipamentos do ateliê, adereços, painéis de fundo, mobílias e roupas. Neles estão referências ao contexto histórico e que se colocam entre o pesquisador e o retratado como uma espécie de ponte. Literalmente, de um lado, está a realidade social. Do outro lado, o fotógrafo, seus pontos de vista e anseios, suas montagens cênicas, seu uso dos recursos técnicos. A análise deve, então, desenhar um movimento que combina diferentes pontos de partida e de chegada: o fotógrafo, o ateliê, a cidade e o país no qual ele atua, cada um desses pólos remetendo invariavelmente ao outro.

Tais imagens obrigam quem as estuda a reconhecer atentamente seus elementos constitutivos. Devemos perceber, por exemplo, pequenos detalhes, tais como, poltronas, colunas, estatuetas e, ainda, um sem número de chapéus, bengalas, sobrecasacas e vestidos. Numa observação atenta, encontramos, ainda, inúmeros painéis de fundos diferentes. Enfim, o espaço da "sala de poses" é um lugar onde se estabelece uma série de formas de representação.

Neste sentido, na análise destas imagens, é pertinente que se dê atenção aos elementos cênicos e às formas de uso das indumentárias, aproximando-se das vontades específicas dos retratados. É relevante o fato de alguns componentes tradicionais, usados nas referidas imagens, tais como móveis e painéis, por exemplo, serem, em alguns casos, substituídos por objetos que fazem referência direta à realidade sociocultural do retratado.

É pertinente, também, que procuremos não só uma aproximação com as interferências do fotógrafo, mas com as suas não-interferências. Pois, em muitos casos, notamos que ele se faz presente dando liberdade ao modelo, abrindo espaço para que este se mostre independente dos modismos predominantes. Outro ponto fundamental para o trato analítico do material é a aproximação para com o contexto histórico na qual se produz a imagem.

Tal movimento permite melhor entendimento dos códigos e linguagens próprios do meio, o que fornece elementos para a compreensão das razões de determinadas opções feitas por retratado e retratista. Fica claro, então, que conhecer a técnica fotográfica é primordial para o estudo de tais ima- 
gens, mas é preciso considerar que além da lógica de produção apresentada há uma carga muito grande da influência do contexto cultural nestes retratos.

Atendendo às demandas sociais, é evidente que a reprodução dos valores da nova ordem política e social que nosso país vive na segunda metade do século XIX, o uso destas fotografias para a construção da auto-imagem de parte da população torna-se um filão recorrente dos ateliês fotográficos, e mesmo as classes inferiores da sociedade, em menor escala, almejam participar dos novos rituais de representação. Modelos típicos desse 'novo homem' são difundidos e, em muitos casos, as representações não conseguem esconder as diferenças de classe, ao contrário, as posições sociais são flagradas, apesar da mis-en-scéne. As fotos denunciam que o pobre, ao se travestir de rico, acaba refém de uma pose demasiadamente rígida e, em grande parte dos casos, podemos notar certo desconforto do retratado diante da indumentária em geral oferecida pelos ateliês. Algumas das vestes usadas são as oferecidas pelo ateliê aos clientes, vindo, inclusive, descosturadas para serem adaptadas ao corpo do retratado, o que evidencia a conjunção entre realidade e ficção, verdade e sonho, imposição social e vontade individual (FABRIS, 1991, p. 21).

Tudo isso numa sociedade - dividida em classes e em universos distintos de homens e de mulheres, de adultos e de crianças - que tem na moda um dos fatores determinantes para a representação de valores e papéis sociais (LEMOS, 1983, p. 58).

Diante do exposto, fica evidente que, para entendermos o dia-a-dia dos profissionais da fotografia no século XIX, e os retratos cartes de visite, devemos considerar o grau de importância da técnica no desenvolvimento do ofício. Constatamos também o papel da subjetividade contida na relação entre retratado e retratista, que assume uma importância cabal no ato fotográfico. Ao procurar o profissional da fotografia, a vontade do cliente é, sem dúvida, uma das determinantes do registro fotográfico. Discutindo acerca dos seus anseios, o retratado estuda com o fotógrafo as possibilidades de construção do registro, do ponto de vista técnico e simbólico. Esta relação entre retratista e retratado se dá sob num contexto social permeado por valores culturais.

Neste sentido, pensar as imagens fotográficas nos obriga, num primeiro momento, a reconhecer que as mesmas são fruto de um contexto social, e marcadas por informações típicas do meio que as produz. Reconhecemos, assim, que não podemos de forma alguma negar a influência do meio na produção 
das fotografias, já que elas são parte de um processo intimamente ligado aos próprios modos de vida da sociedade que as produz. Sendo, inclusive, as significações existentes nos registros, imagens que estas sociedades projetam de si mesmas e que, num segundo momento, encontram seu sentido ao serem projetadas no meio social, permeados de códigos particulares do próprio ambiente que as produz.

\section{Christiano Junior, as ruas do Rio de Janeiro na sala de poses}

Nascido no ano de 1832, na Ilha das Flores, arquipélago de Açores, Portugal, José Christiano de Freitas Henriques Júnior se muda para o Brasil no ano de 1855 , chegando ao país acompanhado de sua esposa e dois filhos. Inicia a atividade fotográfica por volta de 1860, na Rua do Comércio, em Maceió, Alagoas, onde mantém estúdio até 1862 . Pouco depois, em 1863, transfere-se para o Rio de Janeiro, inicialmente atendendo no Hotel Brisson, na Rua da Ajuda, 57-B; um ano depois, ele está no Photographia do Comércio, à Rua São Pedro 69, tendo como sócio Fernando Antonio de Miranda. Em 1865, tem ateliê na Rua da Quitanda 53 (para melhor compreensão, vejamos o mapa 3, página 202, do acervo da Biblioteca Nacional), desta feita, sozinho (ERMAKOFF, 2004, p. 122). Pouco depois, em 1866, associa-se a Bernardo José Pacheco e funda o ateliê Christiano Jr. \& Pacheco.

Seu ateliê é mais um na cidade a disputar a clientela, sendo frequentado por mais de um segmento social. Mas, o que diferencia o seu trabalho, na sua passagem pelo Rio de Janeiro, e o que nos chama mais a atenção, são os retratos da população cativa da cidade. Realizado no suporte carte de visite, as imagens foram produzidas em dois padrões: retratos de corpo inteiro e bustos. Foi em 1866 que o Almanak Laemmert anuncia a venda de uma "Variada coleção de costumes e tipos de pretos, coisa muito própria para quem se retira para a Europa", tal anúncio pode ser visto na figura 1 . Sua série, vendida no seu próprio estabelecimento e também na Casa Leuzinger (LAGO; LAGO, 2005, p. 133).

Pelo ano da realização, as imagens foram feitas especificamente quando ele trabalha sem sociedade, mas este acervo veio a ser incorporado à gama de produtos do ateliê Christiano Jr. \& Pacheco. 
Tais imagens espelham as ruas do Rio de Janeiro. À época em que as fotografias são produzidas, a população de negros escravos que trabalham nas ruas da cidade é de 55.000 pessoas, 1/3 do total da população da capital, sendo que, em alguns momentos do século XIX, chegou a ser metade da população total (GORENDER, 1988, p. 93). Em algumas das fotografias, principalmente nas de busto, encontramos anotações que identificam a nação africana da qual o negro registrado é originário. Isso, a nosso ver, demonstra por parte dele uma grande preocupação em evidenciar a diversidade dessa população.

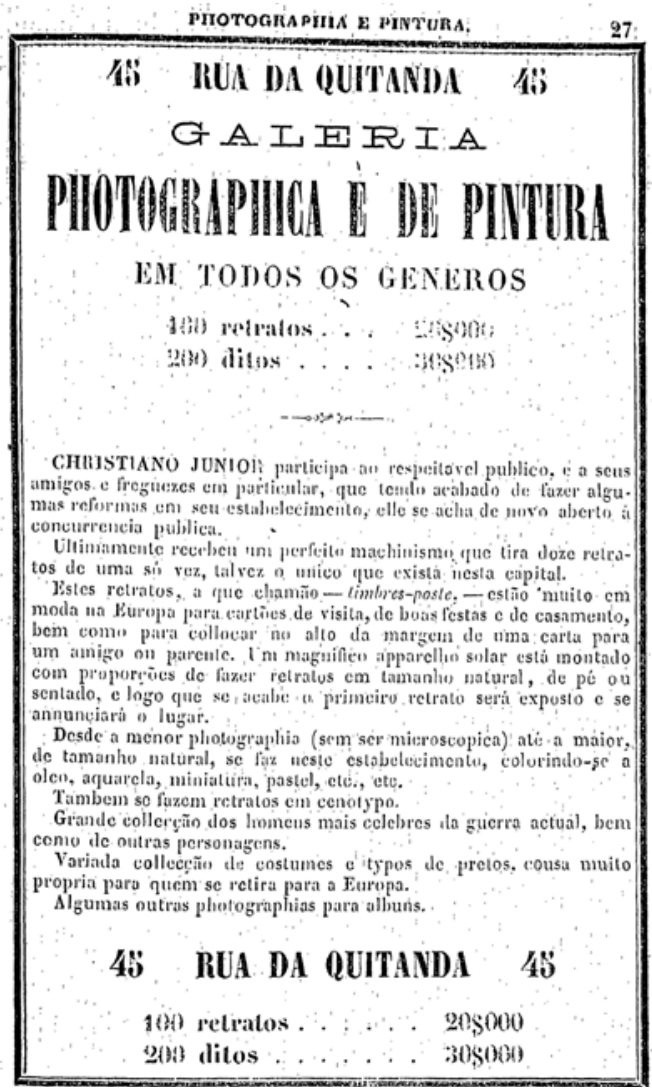

Do ponto de vista comercial, tal modalidade fotográfica é um produto da época, e feito por outros profissionais em nosso país, configurando-se uma modalidade muito difundida. Dentre outros profissionais que desenvolveram trabalhos deste tipo destacamos Alberto Henschel, em Pernambuco, João
Figura 1

Reproduzida do Almanak Laemmert 1866, "Notabilidades" p.27 
Goston e Rodolpho Lindemann, na Bahia, e Felipe Augusto Fidanza, no Pará, mas nenhum o fez com a dimensão do seu trabalho, pois até o momento já foram reconhecidas mais de 100 imagens diferentes (LAGO; LAGO, 2005, p. 133). Dentre o material deixado por Christiano, os retratos de corpo inteiro são aqueles que mais nos chamaram a atenção, são neles que vemos os negros executando os mais diferentes ofícios, típicos dos escravos de ganho: vendedores de frutas, barbeiros, amoladores de facas, carregadores, entre outros. Estas imagens são vendidas no comércio local e servem como uma espécie de souvenir dos trópicos, sobretudo, útil ao imaginário que acompanha os viajantes que por aqui passam. A forma de compor a imagem, deixando quase sempre o fundo sem nenhuma informação, permite que o modelo, no primeiro plano, ganhe destaque.

Embora seja inegável a presença de motivação mercadológica, esse elemento não compromete a importância do trabalho de Christiano Jr, pois salta aos olhos a forma extraordinária com que ele traduziu em imagens esse segmento social. As imagens mostram por parte dele um engajamento especial, seja por sua grande quantidade de tipos, pela diversidade de ofícios mostrados ou pelas próprias vestimentas. Nesse sentido, seu trabalho não apenas se destaca em relação à concorrência, colocando um novo produto fotográfico para o mercado, como também constrói um conjunto de imagens que destacam o cerne da sociedade da capital imperial. Esses homens e mulheres, na sociedade escravocrata, desempenhavam uma infinidade de funções, numa sociedade cuja conotação do trabalho braçal é pejorativa.

Para observarmos a forma pela qual ele registrava, abrindo a série de vendedores temos as figuras 2 e 3. Na figura 2, carregando uma cesta sustentada pelo braço esquerdo, o homem faz uma pose que sugere que ele está a caminhar. Com um chapéu na cabeça e visto de perfil, a cena ganha movimento; seu paletó está abarrotado e apresenta manchas. Sua expressão é fechada, olhar direcionado para uma das laterais do ateliê, sem, no entanto, que o modelo se coloque totalmente de lado, ele tem uma leve inclinação para a direita. Esses homens circulavam pela cidade ou ficavam em pontos estratégicos, aguardando algum trabalho como carregador.

Na figura 3, vê-se um artesão. Ele ostenta um ar sério, que deixa sua testa franzida; seu olhar é direto para o fotógrafo. Sua roupa é uma calça preta e blusa branca. Na cabeça, um gorro bastante justo. O retratado simula a fabricação de algum 
objeto feito de palha, e a posição ostentada faz com que seus pés descalços ganhem um destaque especial na composição. A técnica de trabalho empregada nessas obras com palha é de origem africana, sendo assim um ofício que, de certa forma, parece menos alienante que os demais (CUNHA, 1988, p. 25).
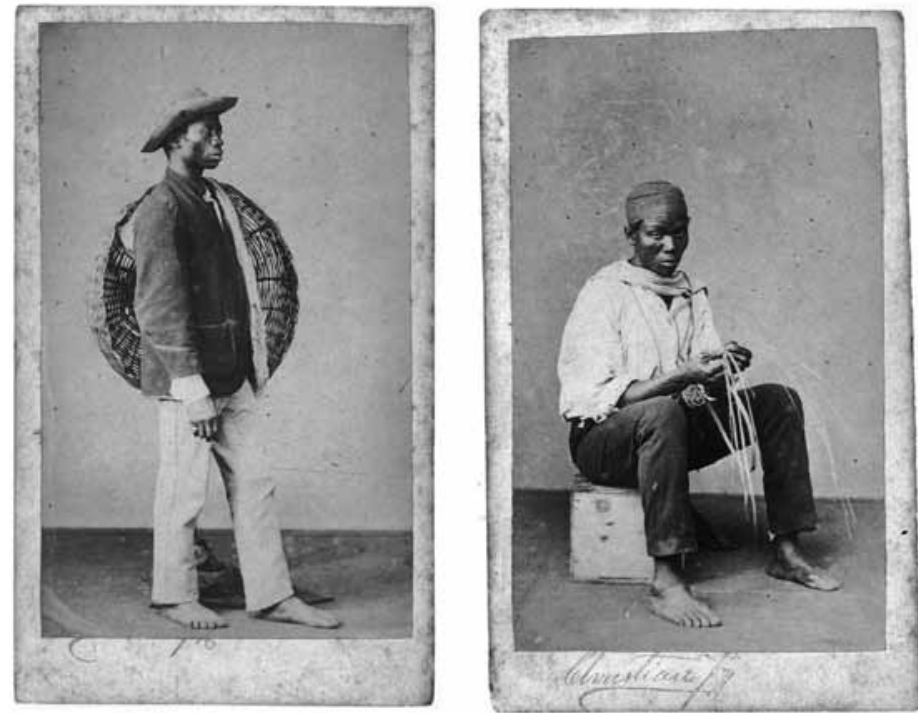

Figuras 2 e 3

Novamente fazendo uso de certa teatralidade própria das ruas, na figura 4 vemos um casal de vendedores. O homem apresenta uma surrada sobrecasaca, sua calça, da mesma forma, está esfarrapada. O serviço de carregador era um dos mais requisitados; qualquer negociante contava com um ao seu lado, pois só o escravo se prestava a esse encargo. Ocupando o espaço das ruas, os escravos assumiram a profissão de vendedores ambulantes, dos mais variados tipos de produtos. Alguns senhores passaram a treinar novos africanos na arte de vender, em vez de servirem simplesmente de carregadores, ampliando a exploração destes. Além de carregadores, alguns vendedores também levavam cestas sobre a cabeça, outros levavam tabuleiros de madeira ou caixas; escravos de ambos os sexos vendiam de tudo:

(...) artigos de vestuário, romances e livros, panelas e bules, utensílios de cozinha, cestas e esteiras, velas, poções de amor, estatuetas de santos, ervas e flores, pássaros e outros animais (...) (GRAHAM, 1988, p. 146). 
Mas os carregadores de todos os tipos são os que mais chamam a atenção daqueles que passam pelo Rio de Janeiro; Debret passa a seguinte impressão acerca desse cenário, relatando ser estranho que “(...) nesse século de luzes se depare ainda no Rio de Janeiro com o costume de transportar enormes fardos (...)", prática essa que “(...) assegura a remuneração diária de escravos empregados nos serviços de rua (...)” atendendo interesses dos proprietários (...) cujos negros todas as noites trazem para casa os vinténs necessários muitas vezes à compra das provisões do dia seguinte" (DEBRET, 1975, p. 238).

Com relação aos vendedores ambulantes, as imagens 4 e 5 nos parecem ser as que, certamente, demonstram maior desconforto dos modelos. Parte dessa impressão pode estar ligada à grande complexidade da produção; aliar o equilíbrio dos produtos sobre a cabeça, com certeza, é um complicador, devido ao tempo de imobilidade necessário para tais imagens. Na figura 4, vemos atrás dos retratados, no chão, um pano que cobre a haste de fixação, é possível notar que o homem segura em uma delas com o braço esquerdo, o que fica oculto por estar coberto pelo corpo da mulher. Ela usa uma vestimenta toda branca, o que provoca um destaque maior com relação ao fundo, fazendo com que o primeiro plano adquira maior expressividade.


Na figura 5 vemos um negro que veste um surrado paletó e segura numa das mãos um chapéu, o que, de certa forma, faz uma paródia dos padrões de vestimenta da época. O objeto 
que ele ostenta é uma sacola, o que pode ser um indicativo de que ele seja um prestador de pequenos serviços, como mensageiros, ou encarregado de pequenas entregas. Interessante é sua roupa, com calças bem postas, paletó de veludo, portando, ainda, um relógio de algibeira, um anel com pedra, chapéu e até um charuto. Mas um detalhe é intransponível, ele tem que andar descalço. Como todos os escravos, ele não calça sapatos, sinal indisfarçável de sua condição de cativo (ALENCASTRO, 1997, p. 19).

Com relação à imagem, assim como a mulher da figura 4, a roupa branca também faz com que o modelo ganhe destaque com relação ao fundo. Aliás, esse fundo apresenta um corte horizontal na parte superior, possivelmente ocasionado pelo enquadramento mais distanciado, provocando o aparecimento do suporte onde poderia estar o painel de fundo. Essa opção por um enquadramento mais distante deixou o modelo menor em relação à cena, aumentando a dramaticidade da composição. Trata-se de um vendedor de água, mais um "negro de ganho", vital para a vida da cidade, são homens que buscam a água nos chafarizes da cidade, levando-a até seus clientes.

Sobre os carregadores em geral, Debret alerta para sua importância, pois eles assumem um papel bastante significativo; nas suas palavras os “(...) negros carregadores, que passeiam com o cesto no braço (...) que se dá o nome de negro de ganho; espalhados em grande número pela cidade (...)", fazem todo tipo de trabalho, tendo se tornado indispensáveis para a sociedade (ALENCASTRO, 1997, p. 19). Na sua detalhada descrição, tais homens podem ser vistos, em algumas ocasiões, carregando minúsculas cargas, pois é considerado “(...) desprezível quem se mostra no Brasil com um pacote na mão, por menor que seja" (ALENCASTRO, 1995, p. 159). Os escravos urbanos estão, na sua maioria, ligados a algum tipo de atividade de carreto, desde carregadores de água e dejetos humanos, passando por carregadores de cadeiras e mercadorias, outros são vendedores ambulantes de uma infinidade de produtos (KARASH, 2000, p. 267).

As figuras 6 e 7 são bons exemplos da preocupação que Christiano Jr. tem com relação ao uso de indumentárias, elementos que enriquecem a composição do modelo. Na figura 6 vemos mais um carregador, segurando o que nos parece ser um galão de leite. De todas as fotografias, parece ser essa a carte de visite na qual o modelo apresenta mais desenvoltura diante do fotógrafo, já que mostra um semblante bastante 
tranquilo. Sua postura chama a atenção, principalmente, por sua forma rígida de posar e seu olhar seguro, buscando algum ponto do ateliê, mas sem abaixar o rosto. A pose é de meio perfil, suas vestes são formadas por um avental branco, que cobre uma roupa da mesma cor. Ele se destaca diante do fundo, todas as variantes narradas dão uma forma especial para o primeiro plano.
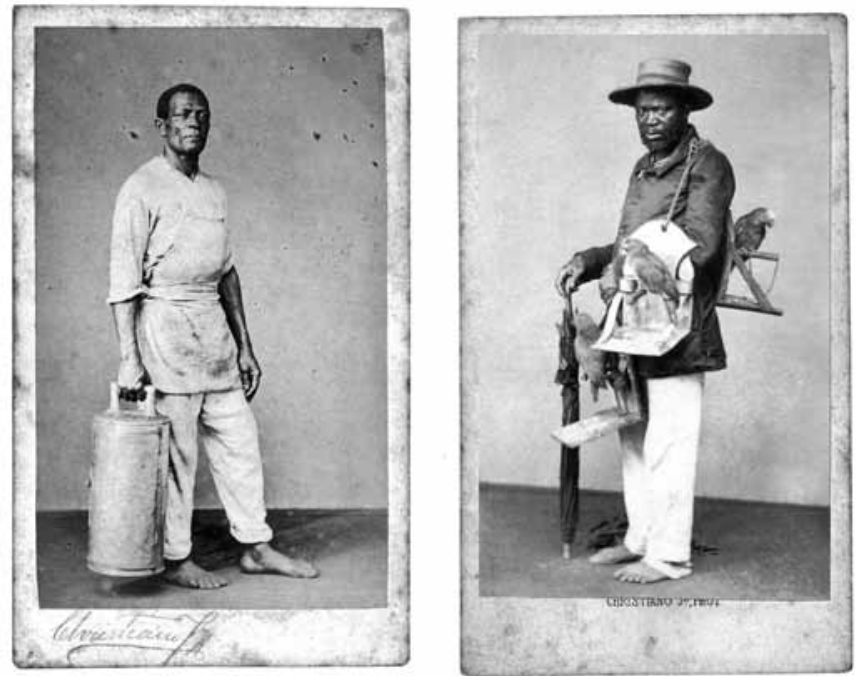

Na figura 7, o vendedor de papagaios se apresenta ostentando alguns símbolos de status, chapéu, paletó e um guarda chuva que, ao servir de apoio, cumpre a função de uma bengala. Inclusive, o objeto dá um equilíbrio à cena, ajudando o retratado na sua postura, que se completa por conta do seu olhar direto e seu ar sereno. Mas a carga de informação de alguns objetos também está ligada à referência da sociedade civilizada; assim, guarda-chuva e chapéu imprimem uma função simbólica. Porém, o detalhe mais interessante na elaboração de tal retrato está na forma pela qual o fotógrafo faz a ornamentação do ofício representado, ornando-o com aves, dispondo-as em três pontos diferentes. Sendo um deles de forma frontal, possibilitando uma perfeita visualização, que se destaca por se posicionar defronte à sua roupa clara. É interessante a preocupação descritiva do fotógrafo, sempre detalhista na apresentação dos objetos relacionados ao trabalho.

Nas figuras 8 e 9 vemos mais dois tipos de vendedores. Na figura 8, pés descalços, calça escura e paletó aberto, mos- 
trando uma vestimenta na cor branca, que ganha destaque. Na posição de meio perfil, ele tem diante de si sua mesa portátil com maçãs, numa encenação do seu ritual de venda, ele aperta uma delas com a mão direita. Ele veste uma calça que está presa por um cinto de couro, uma camisa branca e, sobre ela, um casaco que faz conjunto com sua calça. Sobre a cabeça uma elegante boina, tendo também sua barba devidamente aparada. Seu olhar se perde em algum ponto do ateliê.

Na figura 9, diante do seu tabuleiro vemos aquele que pode ser um escravo de pele clara, tal fato, mesmo ocorrendo em menor proporção, acontecia. O simples fato de os brancos, mesmo os mais miseráveis, negarem-se a fazer tais ofícios, comprova ser mesmo uma confirmação da condição escrava do retratado (GORENDER, 1988, p. 29). Luis Felipe de Alencastro afirma que este fato foi ignorado pelo censo de 1872 , que, numa decisão eminentemente ideológica considerou todos os escravos como negros ou pardos, ignorando essa minoria de brancos filhos de mães escravas (ALENCASTRO, 1997, p. 89).
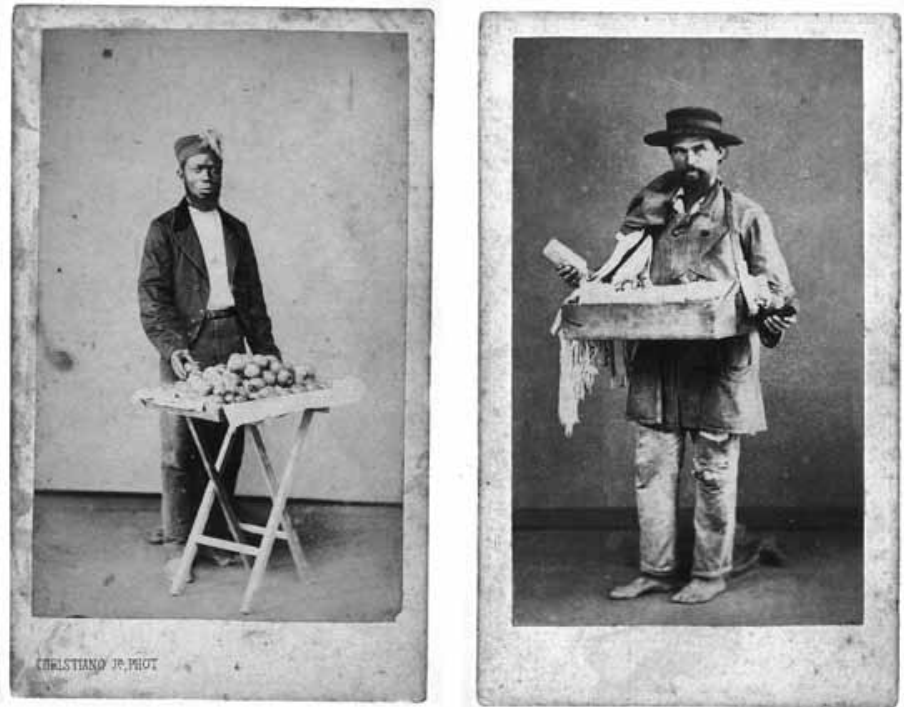

Figuras 8 e 9

Sigamos, observando as figuras 10 e 11 . A figura 10, cujo retratado apresenta um barbeiro, personagem extremamente importante na cena urbana e anteriormente reproduzido em aquarela por Jean Baptiste Debret. Aliás, segundo nos parece, é provável que Christiano tenha conhecimento acerca dos trabalhos dos desenhistas e pintores do início do século, já que suas 
fotografias dialogam de perto com eles. Posando como a totalidade dos modelos, ele está descalço, simbolizando inequivocamente, aos olhos do estrangeiro, sua condição de escravo. Ele veste calça, camisa e paletó; nas mãos vemos seus instrumentos de trabalho, um pente e uma tesoura. Ser assim retratado, manipulando seu instrumento de trabalho, comprova de certa forma a sua habilidade para a profissão, o que indicava alguma distinção, quando comparado a outras modalidades de serviço, tais como carregadores, por exemplo. Depreende-se, então, que a especialidade configura para ele uma posição mais elevada na hierarquia, podendo significar até a possibilidade de fazer economia para comprar a própria alforria. Outra questão relevante é o fato de eles serem, ao mesmo tempo, as pessoas que poderiam, dentro do seu próprio grupo, resolver problemas odontológicos ou da área médica.
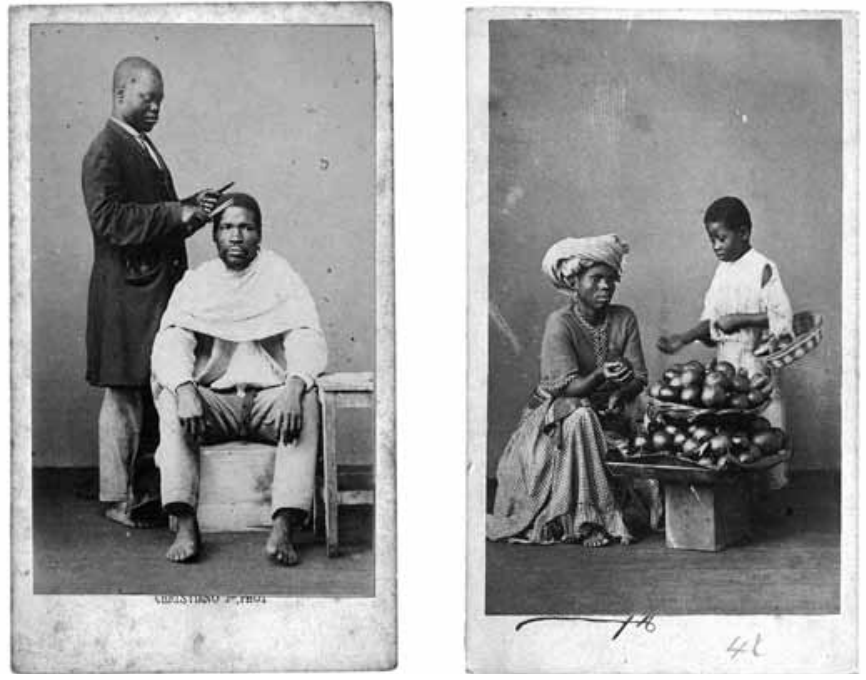

Na figura 11 atentamos para uma vendedora de legumes; usando uma espécie de turbante na cabeça, ela está com um vestido cujo tecido é quadriculado, e, sob este, aparece um de seus pés, denunciando a sua condição de cativa. No seu rosto também vemos as marcas étnicas, cicatrizes simétricas que são sinais de costumes tribais (GORENDER, 1988, p. 29). Em uma das mãos, ela segura um dos seus produtos e, em mais um exemplo de encenação, o menino ao seu lado simula estar adquirindo o produto. Possivelmente, a cena transpõe para a sala de poses um pedaço da praça 'mercado de legumes', onde 
as vendedoras se reúnem todas as manhãs (DEBRET, 1975, p. 232). É interessante pensarmos que tais fotografias são pedaços da cidade recompostos no ateliê e, certamente, quando isso ocorre o retratado é aquele que compreende com muito mais propriedade o seu próprio universo.

A série de retratos de "negros de ganho" de Christiano Jr., parcialmente analisadas por nós, gera discussões com enfoques variados. A primeira colocação sobre o material foi feita pela antropóloga Manuela Carneiro da Cunha, em 1988. Segundo sua apreciação, nos parece que a grande diferença com relação à nossa leitura radica no fato de não existir a típica relação entre o retratista e retratado na sua elaboração. Para ela, o retratado, categorizado como 'coisa', surge totalmente distanciado do processo de produção das imagens, reduzido a mero objeto. Ainda, segundo a autora, se o homem livre tem a sua imagem formalizada por meio de uma carte de visite, o retrato do escravo se dá na forma de cartão postal: “(...) um quer descrever a pessoa, digna e singular, outro descreve o personagem, pitoresco e genérico" (CUNHA, 1988, p. 24). Ao que nos parece, ela crê que, ao participarem da cena fotográfica, os escravos perdem a sua condição humana, tornando-se objetos. Ainda segundo a autora:

Num retrato pode-se ser visto e pode-se dar a ver, alternativas que estão francamente ligadas à relação do retratado com o retratante. Quem encomenda uma fotografia mostra-se, dá-se a conhecer, esparrama-se pelo papel, a si e a seus atributos e propriedades, como gostaria de ser visto, como se vê a si mesmo no espelho. É o sujeito do retrato. Aqui o escravo é visto, não se dá a ver. (...) (CUNHA,1988, p. 23).

Entendemos que tal colocação ignora a mediação do fotógrafo que, ao estar diante de um escravo, na visão apresentada, desaparece, perdendo-se a relação de troca entre retratista e retratado. É um ponto de vista que descarta toda a relação subjetiva que, mesmo num encontro de desiguais, subsiste. Não se trata, aqui, de desqualificar a brutalidade da escravidão, mas sim, de reconhecer a mediação do fotógrafo na produção da imagem. Pois, inevitavelmente, a cena que vemos é elaborada num processo amplo, possivelmente iniciado na negociação, depois a chegada ao ateliê, escolha de indumentária ou manutenção da vestimenta original, e elaboração efetiva da fotografia, a fixação do modelo, tarefa que, segundo observamos, não é das mais fáceis. Outra questão é que os retratados são perso- 
nagens cotidianamente envolvidos no ir e vir da cidade. Num certo momento, a própria autora confirma isso e diz que:

Os negros de ganho estão por todo o Rio de Janeiro. Ocupam as ruas da cidade. Sustentam-se, a si e a seus senhores, dos mais ricos àqueles caídos na miséria, para quem um negro de ganho, por velho que seja, é o único recurso (...) (CUNHA, 1988, p. 24).

Ou seja, eles estão efetivamente influindo na cena local, interagindo com o cotidiano da cidade, fato que explica a geração dessas imagens, frutos desse ambiente. Essa realidade vista nas fotografias não pode ser captada como algo distante e remoto, já que o 'objeto' em questão é algo permanentemente ligado ao dia-a-dia da cidade. Fotografá-los, para Christiano Jr., é mais uma forma de se relacionar com eles, dentre tantas relações cotidianas que são estabelecidas, inclusive pelo próprio Christiano Jr., com esses indivíduos

Mais recentemente, novamente a bibliografia nacional engrossa a perspectiva de que tais imagens praticam a 'coisificação' dos retratados. Em publicação recente, Pedro Vasquez diz que o fotógrafo fez uso dos modelos para ganhar 'dinheiro fácil', equiparando a série a uma coleção de insetos, presos nas vitrines da coleção de um entomologista (VASQUEZ, 2002, p. 23-24). Interessante divergirmos, promovendo uma reflexão sobre isso, pois segundo nosso viés de compreensão, construído nesse trabalho, o fotógrafo é percebido como um mediador.

Assim, ao direcionarmos nosso olhar para outra possibilidade, que não refuta, mas acrescenta novas suposições àquela proposta por Vasquez, invertemos a colocação, pois o que fica patente é o não reconhecimento do indivíduo que faz a imagem, bem como a negação de sua relação com o retratado. Parece-nos que essa vertente de interpretação é que coisifica tanto o retratado como o retratista, transformando-os em meros objetos. Um fato que parece ser ignorado refere-se à existência de uma relação de aproximação, compreensão e re-construção da imagem 'do outro'. Se o escravo é mostrado nas cartes de visite como ele é visto nas ruas, é porque ele não passou pelo corriqueiro processo de transformação, observável na maioria das imagens deste tipo.

Sugerimos que é injusto responsabilizar o autor das imagens pelo fato de mostrar 'as coisas' com certo realismo. Num certo sentido, é uma forma de desvelar-se, inclusive, muito próxima daquela que determina o seu próprio olhar sobre os 
retratados. No mesmo sentido, Sandra Koutsoukos aponta que “(...) os modelos posaram para Christiano sempre com dignidade, a eles parece que sempre foi dado um certo grau de controle da própria imagem (...)" (2010, p. 128). Ainda, segundo a autora, se a função das imagens era a de servir como souvenir, hoje elas são, a bem da verdade, documentos históricos.

Aceitando-se que o produto final objetiva vender o exotismo, por outro ângulo de análise torna-se possível assimilar que os retratos colocam os escravos no cerne da modernidade, socializando a imagem das próprias contradições do país. É verdade, também, que a fotografia permite que o retratado, mesmo sendo escravo, se posicione dentro do seu próprio grupo, já que as referidas imagens são expostas nas vitrines dos estabelecimentos. Inclusive, um retratado pode ter funcionado como mediador da contratação de outros modelos.

A exploração da vertente do pitoresco não teve início com a modalidade fotográfica, mas já existia, tradicionalmente, nos desenhos, litogravuras e aquarelas, denotando explícitas finalidades comerciais. Independente do fato de a fotografia ter aderido a esse padrão mercadológico, a projeção e circulação das referidas imagens assumiu várias outras funções, prestando-se a novas nuances de interpretação.

Outra diferenciação necessária é a que deve ser feita e que, a nosso ver, pode promover interpretações equivocadas. Estamos nos referindo à confusão entre a confecção desses retratos e aqueles voltados aos estudos antropométricos, servindo a teses científicas. Tais registros não aderem às formas clássicas de elaboração do retrato, possuindo padrões próprios de produção. Neles, a cabeça do modelo é retratada sempre em duas posições distintas: de frente ou de perfil. Na maioria das vezes, os indivíduos são retratados sem vestimenta, posicionados de pé e com os braços pendentes ao lado do corpo. O que se pretende é que o registro fotográfico do corpo humano resulte em dados fotométricos extremamente claros, que permitam a obtenção de informações confiáveis e passíveis de comparação. O fato é que as imagens feitas por Christiano não tem a função de controle, antes, são releituras da vida nas ruas do Rio de Janeiro.

Pouco depois de fazer tais registros, por recomendação médica, em 1866, Christiano Jr. deixa o Rio de Janeiro, seguindo rumo ao Sul; fixou-se por pouco tempo em Santa Catarina, na cidade de Desterro e em Mercedes, no Uruguai. Contudo, seu objetivo era Buenos Aires, onde no ano de 1867 ele se instala à Rua Florida 159. Na ocasião o jornal La Tribuna, em 20 de outubro de 1867 , anuncia a sua chegada à cidade. Interes- 
sante é o fato de o estabelecimento Christiano Júnior \& Pacheco se manter em atividade, mesmo com a saída de Christiano do país, o que pode significar a manutenção da sociedade. No ano de 1872 , quando sabemos que ele já não atua no Rio de Janeiro, o Almanak Laemmert anuncia o ateliê, como podemos ver na figura 12.

Na capital da Argentina o fotógrafo inicia uma maciça produção de retratos. Estima-se que foram produzidos por ele mais de 4.000 retratos, entre 1873 e $1875^{1}$. Como prova de seu sucesso, temos o fato dele ter inaugurado outro ateliê, desta feita, voltado ao público infantil. Denominado Fotografia de La infância, a casa é, segundo anúncio publicado no jornal La Prensa, de 04 de fevereiro de 1875, possuidora de "máquinas instantáneas que permiten sacar retratos de criaturas inquietas y traviesas" (ABEL; PRIANO, 2002, p. 23). O Fotografia de La Infância é destruído por um incêndio, em março de 1875 . Porém, foi reaberto logo depois, à Rua Victoria 296, agora dirigido pelo filho, Jose Virgilio, que anteriormente havia sido seu ajudante.

Ainda no ano de 1875, Christiano torna-se fotógrafo oficial da Sociedade Rural Argentina e realiza sua primeira exposição pela entidade, da qual se desliga em 1878 . Aos poucos Christiano amadurece a ideia de confeccionar um álbum de vistas e, em 1876, lança o primeiro volume da coleção intitulada Album de Vistas y Costumbres de La Argentina. Composto por 16 imagens da cidade de Buenos Aires, o álbum possui textos explicativos em quatro idiomas.

No ano de 1877 sai o segundo volume, contando com doze retratos de tipos populares urbanos e com vistas de constru- 
ções modernas e históricas. No ano de 1878 , seu estúdio é vendido para Witcomb \& Mackern, exatamente quando ele estava vivendo seu melhor momento. A opção em largar o ateliê é motivada pelo desejo de continuar a série de álbuns de Vistas e Costumes da República Argentina. O fotógrafo, agora, se atira numa fantástica peregrinação pelas mais variadas regiões do país, entre os anos de 1879 e 1883. Passa pelas cidades de Rosário, Córdoba, Río Cuarto, Mendoza, San Juan, San Luis, Catamarca, Tucumán, Salta e Jujuy.

Antes de chegar às cidades, anuncia nos jornais locais que ali prestará seus serviços. Monta seu estúdio associado a um fotógrafo local e, em alguns casos, acompanhado de seu filho. Uma vez instalado na localidade, dá início ao trabalho no ateliê e, paralelamente, desenvolve seu projeto maior: os álbuns de vistas. Sua andança é feita sobre várias mulas, que levam uma parafernália em equipamentos. Seu trajeto e alguns detalhes dessas suas viagens podem ser constatados pelos jornais das cidades por onde passa (ABEL; PRIANO, 2002, p. 32-36).

As dificuldades financeiras para tocar um projeto tão complexo obrigam-no a pedir ajuda nas províncias que visita, onde, infelizmente, nem sempre é atendido. Desta forma, as dificuldades financeiras atrapalham seus planos. Sua obstinação e paixão pela fotografia não são suficientes para a conclusão do trabalho.

Christiano Júnior vem a falecer, aos 70 anos de idade, no dia 19 de novembro de 1902, em Assunção, Paraguai. A revista portenha Caras y Caretas publica uma nota, na qual informa que ele passou seus últimos tempos pintando fotografias. Quando faleceu, esse homem que a tantos emprestou seus olhos estava praticamente sem nenhuma visão. As imagens deixadas no Brasil por Christiano Júnior testemunham a peculiaridade de seu modo de ver e, sem dúvida, constituem-se na referência incontornável para a reflexão a respeito da história social do nosso país.

\section{Referências}

ABEL, Alexander; PRIAMO, Luis. Recordando a Christiano. Un País en Transición - Fotografías de Buenos Aires, Cuyo y el Noroeste. Christiano Júnior 1867 - 1883. Buenos Aires: Ediciones Fundación Antorchas, 2002.

ALENCASTRO, Luis Felipe (org.). A História da vida privada no

Brasil - Volume II. São Paulo: Companhia das Letras, 1997. AZEVEDO, Paulo Cesar de; LISSOVSKY, Mauricio (org). Es- 
cravos brasileiros do século XIX na fotografia de Christiano $J r$. São Paulo: Ed. Ex Libris Ltda., 1988.

CUNHA, Manuela Carneiro da. Olhar Escravo, Ser Escravo, In: AZEVEDO, Paulo Cesar de; LISSOVSKY, Mauricio (Org.). Escravos brasileiros do século XIX na fotografia de Christiano Jr. São Paulo: Ed. Ex Libris Ltda., 1988.

DEBRET, Jean Baptiste. Viagem pitoresca e histórica ao Brasil - Vol 1. São Paulo: Livraria Martins Editora, 1975.

ERMAKOFF, George. O negro na fotografia brasileira do século XIX. Rio de Janeiro: G. Ermakoff Casa Editorial, 2004.

FABRIS, Annateresa. Fotografia usos e funções no século XIX. São Paulo: Edusp, 1991.

FREUND, Gisèle. Fotografia e Sociedade. Lisboa: Dom Quixote, 1986.

GRAHAM, Sandra Lauderdale. House and street. The domestic world of servents and masters in nineteenth-centuryRio de Janeiro. New York: Cambridge University Press, 1988.

GORENDER, Jacob. A face escrava da Corte Imperial, In AZEVEDO, Paulo Cesar de; LISSOVSKY, Mauricio (Org.). Escravos brasileiros do século XIX na fotografia de Christiano Jr. São Paulo: Ed. Ex Libris Ltda., 1988.

KARASCH, Mary. A vida dos escravos no Rio de Janeiro; 1808 1850. São Paulo: Cia. das Letras, 2000.

KOSSOY, Boris. Realidades e Ficções na Trama Fotográfica. São Paulo: Ateliê Editorial, 1999.

KOUTSOUKOS, Sandra Sofia Machado. Negros no estúdio do fotógrafo. Campinas: Editora da Unicamp, 2006.

LAGO, Bia Corrêa do; LAGO, Pedro Corrêa do. Os fotógrafos do Império. Rio de Janeiro: Capivara, 2005.

LEMOS, Carlos. A ambientação ilusória, In MOURA, C. E. Marcondes de (Org). Retratos Quase Inocentes. São Paulo: Nobel, 1983.

VASQUEZ, Pedro Karp. A Fotografia no Império. Rio de Janeiro: Jorge Zahar, 2002.

NOTAS

1. Com a pretensão de conhecer melhor o perfil de Christiano Júnior, estivemos, em novembro de 2004, no Archivo General de La Nación, em Buenos Aires; na visita pudemos conhecer a produção dele no referido país. Tal aproximação, a nosso ver, confirmou o viés etnográfico do seu trabalho e sua busca em conhecer a cultura das sociedades na qual ele vive.

Recebido em: 31/03/11

Aceito em: 31/05/11 
MARCELO EDUARDO LEITE

marceloeduardoleite@gmail.com

Fotógrafo com formação interdisciplinar, bacharel em Ciências Sociais pela UNESP e doutor em Multimeios pela UNICAMP. Atualmente é Professor adjunto I de Fotografia e Fotojornalismo na Universidade Federal do Ceará, Campus Cariri. 